\title{
Use of Platelet Rich Plasma (PRP) in the Treatment of Acute Post Intubation Tracheal Rupture: Report of Two Cases
}

\author{
Patricio Rioseco $S^{1}$, Sergio Tapia $Z^{1}$, Verónica Céspedes $S^{2}$, Juan Pablo Silva $C^{3}$, \\ Paulina Lozano $\mathrm{F}^{3}$ \\ ${ }^{1}$ Respiratory Unit, Hospital Las Higueras, Talcahuano, Chile \\ ${ }^{2}$ Transfusional Medicine Unit, Hospital Las Higueras, Talcahuano, Chile \\ ${ }^{3}$ Internal Medicine, Universidad de Concepciòn, Concepciòn, Chile \\ Email: parioseco@gmail.com
}

Received 25 May 2015; accepted 7 July 2015; published 10 July 2015

Copyright (C) 2015 by authors and Scientific Research Publishing Inc. This work is licensed under the Creative Commons Attribution International License (CC BY). http://creativecommons.org/licenses/by/4.0/

\section{(c) (i) Open Access}

\begin{abstract}
The use of PRP involves a complex network of molecular events which accelerate tissue regeneration due to its richness in growth factors plus a variety of biologic mediators. Several communications tell us about its usefulness on the dental implantology field, plastic surgery, orthopedics and peripheral nerve regeneration after trauma. We have presented our successful experience of its use in pneumology when treating severe hemoptysis, respiratory fistulae, spontaneous pneumothorax and one tracheal rupture. In this article we present two cases of post intubation tracheal rupture successfully treated with the local instillation of PRP on one of them and with the injection of PRP along the lips of the tracheal wound on the other. Tracheal rupture is a rare but life threatening complication of emergency intubation requiring an effective response in order to avoid the risk of patient death due to secondary mediastinitis and sepsis. Up to now there is no general consensus in the treatment of this condition and alternatives in use are not universally accepted. The use of local autologous PRP in our experience has demonstrated a favorable performance in such cases, turning it in a highly promising tool for the treatment of conditions such as this, in which a rapidly effective and minimally invasive handling is required.
\end{abstract}

\section{Keywords}

Tracheal Rupture, Endotracheal Intubation, Platelet Rich Plasma 


\section{Introduction}

Platelets are anucleated blood elements whose cytoplasm is rich in granules containing a variety of biologically active substances. The Alpha granules are the most numerous and contain fibrinogen, immunoglobulins and growth factors [1]. Delta granules contain adenosine diphosphate, tissue plasminogen activator and serotonin [2] and less numerous Lambda granules contain lysosomal enzymes [3].

Growth factors are proteins that influence the repair and neoformation of soft and bone tissue. The release of these factors in the site of injury by activated platelets acts on the cells that are part of the tissues adjacent to the lesion inducing changes in proliferation, differentiation, protein synthesis and chemotaxis. The damaged area begins to be repaired within three minutes; degranulation of platelets has occurred lasting action of growth factors for approximately eight days.

The alpha granules of platelets contain PDGF (platelet-derived growth factor) involved in pre-osteoblast and fibroblast proliferation, chemotaxis and extracellular matrix formation, TGF (transforming growth factor), useful in chemotaxis and extracellular matrix formation, EGF (epidermal growth factor) that affects fibroblast proliferation and chemotaxis, IGF (insulin growth factor) that influences the proliferation of pre-osteoblasts, chemotaxis and extracellular matrix and VEGF (vascular endothelial growth factor) useful in angiogenesis [1].

It is considered that PRPa volume of autologous plasma contains 4 to 8 times platelets more than normal plasma, that is, about 300,000 to $1,000,000$ platelets per deciliter; the method for its obtaining is quite simple with minimum equipment required.

\section{Obtaining of PRP}

A sample of 20 to 40 cc of venous blood of the patient, with sodium citrate is centrifuged to $280 \mathrm{G}$ for 8 minutes thus separating blood elements into 4 layers; a superficial one rich in plasmatic proteins, an intermediate layer with 2 components, the superior one with a poor amount of platelets and a profound one rich in platelets which is the true PRP, a layer of white elements and finally a $4^{\text {th }}$ layer where red blood cells are deposited.

By means of selective pippeting the platelets rich layer is retired and platelets are activated by the introduction of calcium chloride $10 \%$ in a dose of 50 micro liters per ml of PRP. Activation of platelets occurs and they start to degranulate.

It has been shown that concentration of PDGFAB is 8.28 times greater in PRP than in normal blood and that of PDGFBB is 9.12 times greater in PR than in whole blood, at the mean time concentration of TGF beta in PRP is 2.55 times more than in whole blood [4] so we can state that increasing the concentration of platelets in the plasma, also increases the concentration of growth factors useful in the control of migration and cell growth, stimulation of the formation of extracellular matrix and consequently useful in the formation of a stable scar.

Tracheal rupture is one of the most serious complication of airway intubation as it is associated with severe complications ranging from disabling functional alterations due to the anatomical damage to mediastinitis and death secondary to sepsis. On one side, occurrence of tracheal tears during intubation is related to different facts namely urgent endotracheal intubation which is the most common situation in Intensive Care, unknown deviations of tracheobronchial tree, repeated intents of intubation, procedural errors like using stylets as guide especially when the operator is unskilled, displacement or removal of the tracheal tube without deflating the cuff or overinflating the cuff as an intention to avoid leaks. Is important to know that the female trachea is shorter and thinner than the male's so the choosing of a proper diameter of the endotracheal tube avoids this complication. On the other side, tracheal laceration may go undiagnosed or be mistaken in the context of a very sick patient and the consequences of a late diagnosis, without an adequate treatment would be devastating. Therefore, a high index of suspicion must be held when facing a recently intubated or extubated patient presenting subcutaneous emphysema or unexpected respiratory or hemodynamic instability which are the most frequent signs of tracheal rupture. For this reason it is important to have an early and effective treatment for this condition. So far, surgical treatment has been the traditional therapeutic approach. In recent years there have been communications of good results with different types of conservative measures [5] nevertheless there is no consensus in stating which patients must be managed with surgical treatment and which can be treated conservatively.

To date we have not found in the review of the available literature communications on the use of PRP for the treatment of acute injuries of the trachea in humans therefore we considered it useful to show the results achieved by our working group in the management of the two patients presented below. 


\subsection{Case 1}

A 52 years old morbid obese lady consults at the Emergency Department of our Hospital with severe Community Acquired Pneumonia in respiratory failure with a Pa02/Fi02 ratio of 120 and obtunded, requiring immediate orotracheal intubation and connection to invasive ventilation. Tracheal intubation was difficult because of extreme obesity, shortness of neck and psychomotor agitation. Immediately after connection to a ventilator programmed with protector ventilation parameters progressive subcutaneous emphysema at the cervical region appeared. The patient evolved initially with arterial hypotension needing vasoactive drugs. The X-ray of thorax aroused the suspicion of overinflation of cuff (Figure 1) and the Computed Tomography of thorax (CT) of thorax depicted lost of continuity of the distal membranous wall of the trachea with air leak into the mediastinum (Figure 2). Bronchoscopy showed a large $4 \mathrm{~cm}$ rupture of the posterior wall of the trachea with protrusion of anterior wall of the esophagus into the tracheal lumen (Figure 3(a)). Broad spectrum antibiotic regime was started (ertapenem).

Due to its immediate supracarinal location, which made impossible to pass the endotracheal tube over the defect to isolate it without causing monobronchial intubation we decided to treat it locally by injecting $30 \mathrm{~cm} 3$ of PRP on each lip of the lesion with a double lumen catheter. Through one of the lumens we injected PRP and through the other we injected Calcium Chloride $10 \%$ in order to obtain in situ activation of platelets and therefore a faster action (Figure 3(b)). In a new CT on the next day there was no evidence of passage of air into the mediastinum. At seven days after the procedure bronchoscopy visualized a fibrin layer at the original place of wound with a scar in formation underneath (Figure 3(c)). The patient was successfully extubated; one week later CT showed a well defined scar at the intervention place and the patient was discharged (Figure 3(d)). One month away she is seen as an outpatient, doing well, with non functional or anatomic sequelae.

\subsection{Case 2}

A 77 years old diabetic hypertensive woman with an ancient cerebrovascular occlusive stroke secondary to chronic atrial fibrillation was brought to the Emergency Department with a four day episode of purulent productive cough, fever and dyspnea. Chest X-ray showed consolidation of right lower lobe for which she was started on antibiotics (claritromicine plus ceftriaxone). Two days after, she is on overt respiratory failure (Pa02/Fi0 103) is transferred to the ICU where she needs emergency tracheal intubation guided with stylet and is started on

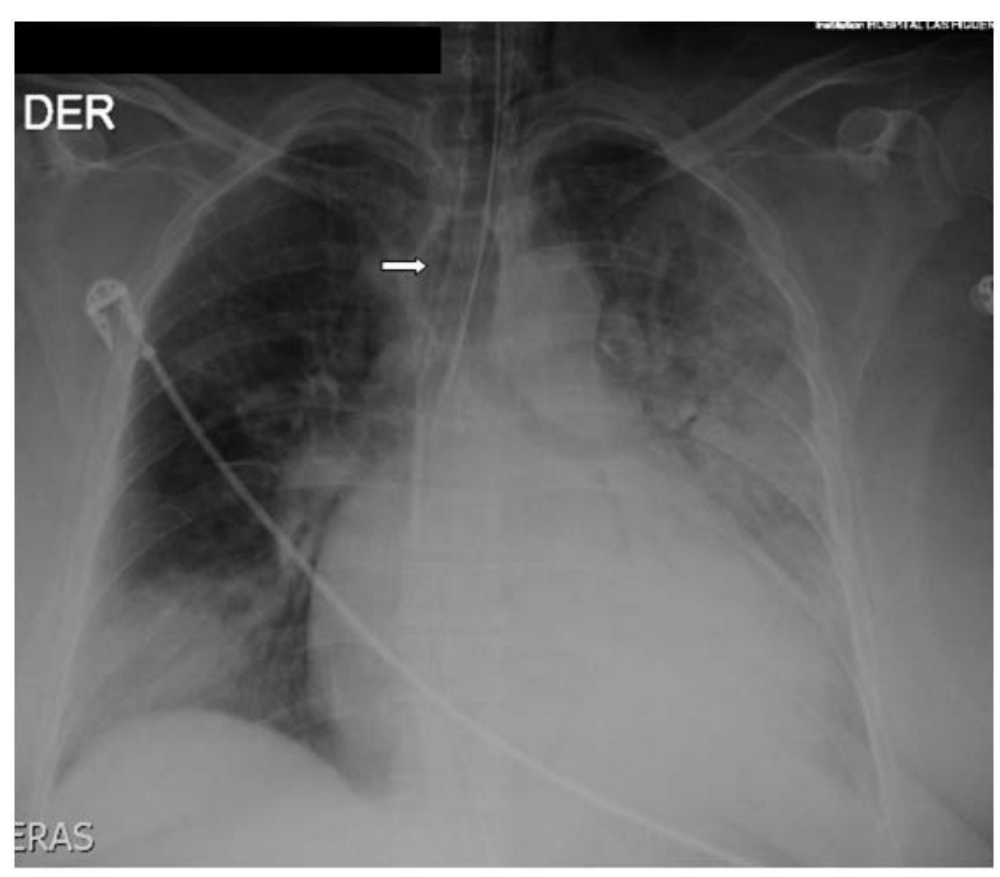

Figure 1. X-ray showing multifocal pneumonia and overinflated endotracheal tube cuff (arrow). 


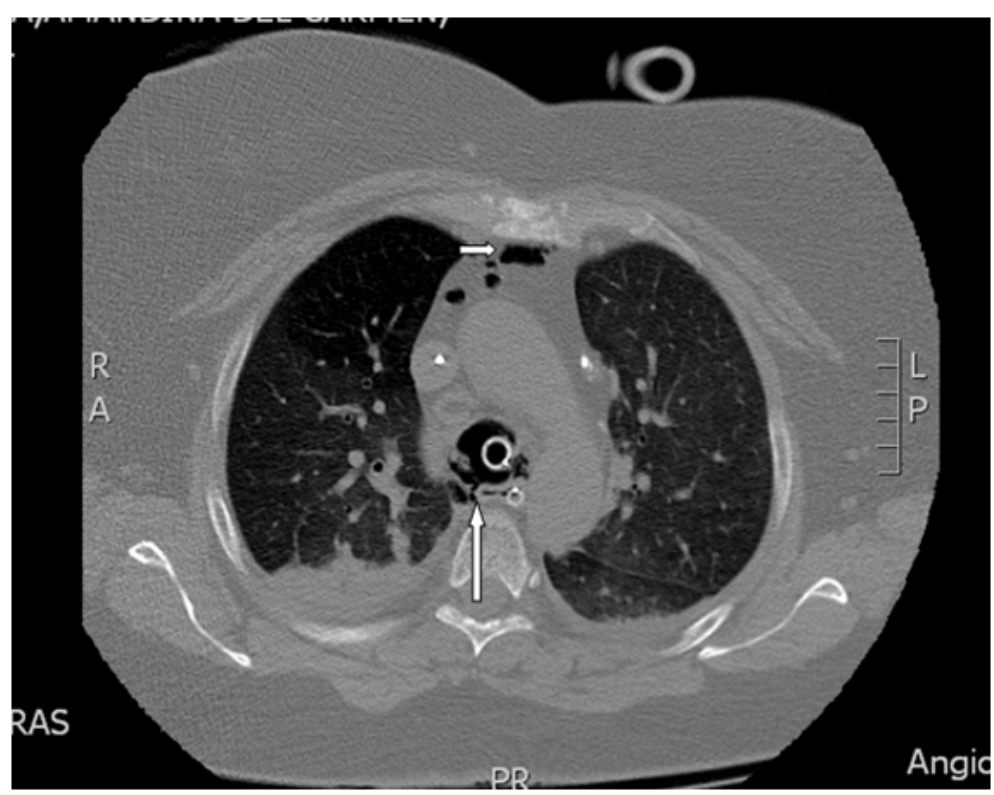

Figure 2. CT scan showing lost of continuity of posterior wall of trachea (long arrow) and air leak into mediastinum (short arrow).
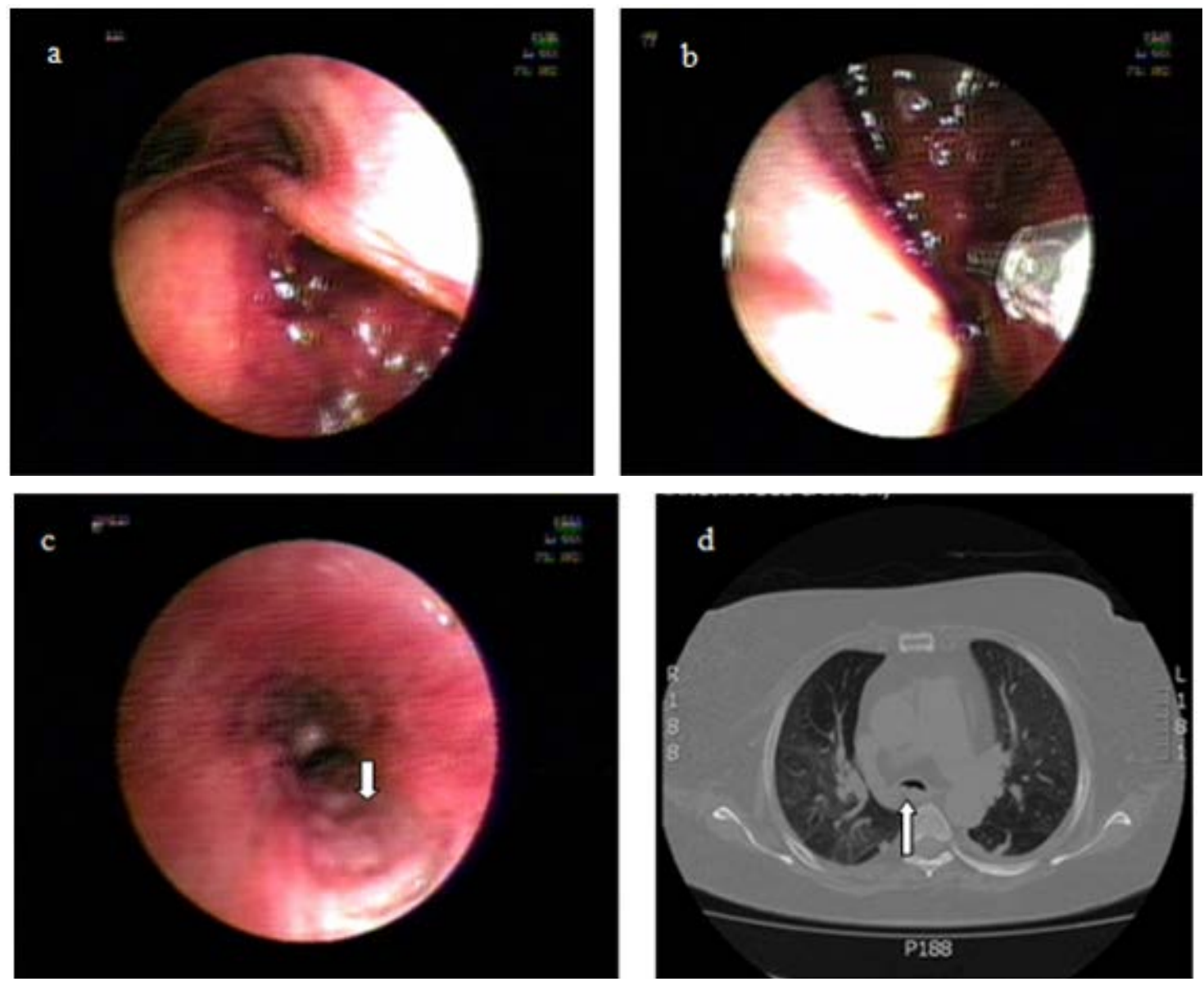

Figure 3. (a) Shows posterior wall of trachea tear; (b) Shows injection; (c) Shows scar after 7 days procedure (arrow); (d) Shows definite scar after 14 days of procedure (arrow). 
protective mechanical ventilation. Two hours later she presents progressive anterior chest subcutaneous emphysema which is clearly visible on chest X-ray (Figure 4(a)) and hemodynamic compromise. CT shows pneumomediastinum severe subcutaneous emphysema without associated pneumothorax and an exophitic lesion in the posterior aspect of the trachea, near the distal end of the endotracheal tube (Figure 4(b)). Bronchoscopy two days after this finding depicted a $5 \mathrm{~cm}$ longitudinal rupture compromising the medium third of the posterior tracheal wall. The endotracheal tube was repositioned with the cuff distal to the lesion and on the next day, we added instillation of $30 \mathrm{~cm}^{3}$ of activated PRP into the wound through bronchoscope. Antibiotic therapy was changed to imipenem plus vancomycin and the following 4 days the patient evolved favorably, a new CT showed a significant reduction of pneumomediastinum and subcutaneous emphysema with indemnity of the compromised tracheal wall (Figure 4(c)). She was extubated and at the $13^{\text {th }}$ day after the procedure, bronchoscopy showed a firm scar at the site of lesion (Figure 4(d)). One month later the patient is well, without respiratory symptoms and bronchoscopy shows indemnity of the posterior wall of trachea.

Tracheal rupture is a rare and serious complication of tracheal intubation, percutaneous dilatational tracheostomy and thoracic surgery as well as blunt chest trauma.

There are a number of risk factors for post intubation tracheal laceration, some related to technical issues and others related to the patient himself; among them is worth to mention: experience of operator, emergency tracheal intubation, use of stylets as guidance, repeated attempts at intubation, use of improper diameter endotracheal tubes, over inflation of cuff and type of endotracheal tube (single or double lumen). On the other side there will be more chances of damage if there are unknown anatomical abnormalities of thachea, if there is psychomotor excitement during intubation or if the patient is an aged (over 50) woman malnourished, obese, short necked, diabetic or under steroid treatment [6] [7]. Massard et al. in a series of 14 post intubation tracheal injuries and Cordillo in 30 post intubation tracheal lacerations describe a $92 \%$ and $93 \%$ predominance in women
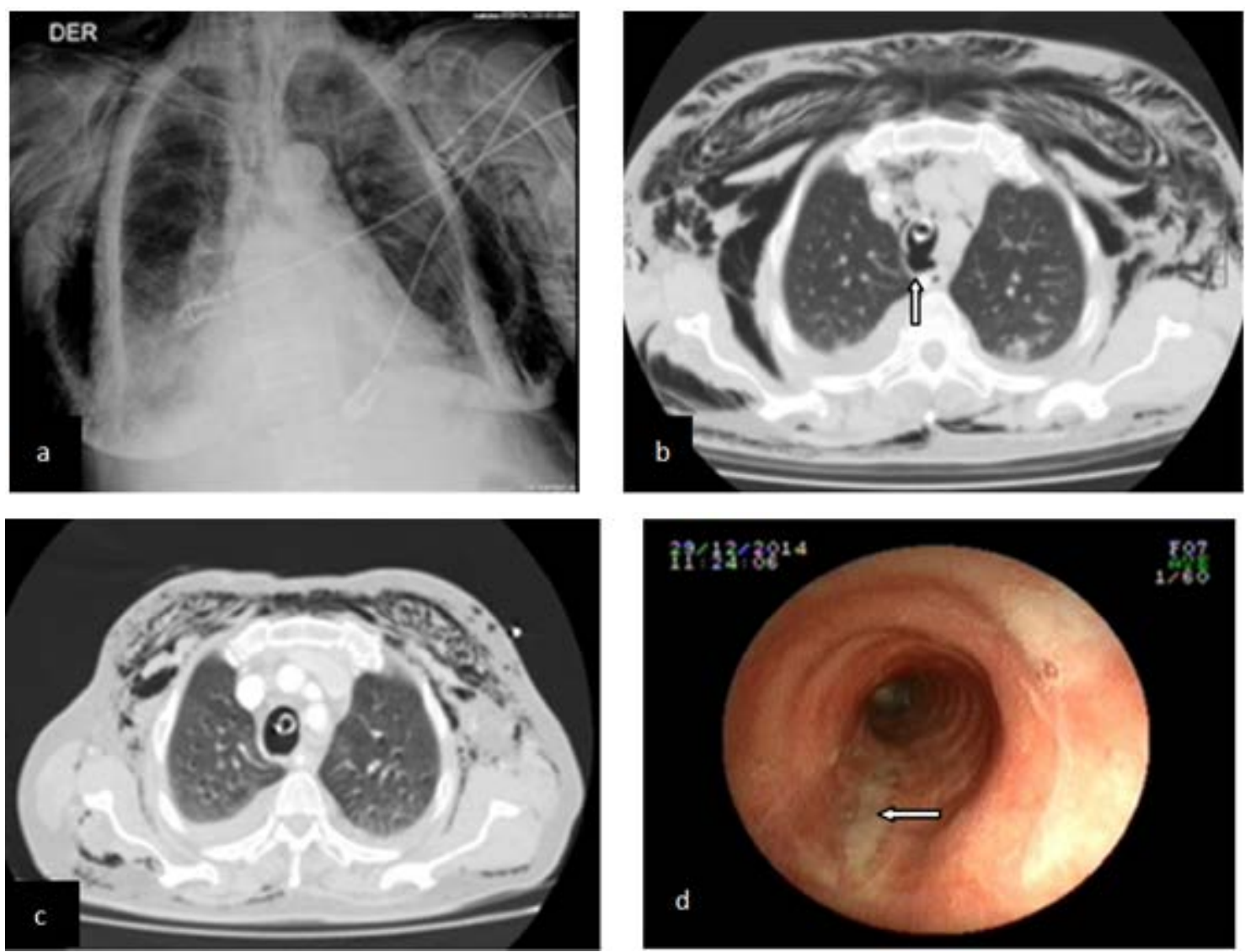

Figure 4. (a) Shows X-ray with extense subcutaneous emphysema; (b) Shows CT with exophitic lesion abouting from posterior wall of trachea (arrow); (c) CT scan showing indemnity of posterior wall of trachea at $4^{\text {th }}$ day after procedure; (d) Endoscopy at $13^{\text {th }}$ day after procedure showing scar (arrow). 
respectively [8] [9].

True incidence of tracheal rupture is unknown but according to reported series approximately 1 out of 575 dilatational tracheostomy, 1 out of 20.000 to 1 out of 75.000 intubation attempts with a single lumen tube and $0.05 \%$ to $0.19 \%$ with a double lumen tube will end up with damage to the tracheal structures [10] and even more, autopsy studies suggest that the actual occurrence may be as high as $15 \%$ of emergency intubations [11]. Many of such complications are undiagnosed, misdiagnosed or not reported at all. Most patients suffering tracheal rupture are women. This sex predominance is explained by differences on anatomical grounds.

The male trachea is longer and wider than the female's. Trachea has an upper coronal and sagittal diameter of 21 and $27 \mathrm{~mm}$ respectively in men and 21 and $23 \mathrm{~mm}$ in women and a lower limit of $13 \mathrm{~mm}$ for males and 10 $\mathrm{mm}$ for females [12].

As in both of our cases location of laceration occurs in the majority of cases in the distal third at the right side of the posterior wall which is the more elastic but least resistant part of the trachea. By contrast, the left side of the posterior wall is protected by the esophagus and therefore is more resistant. Both patients presented in this report had risk factors: female sex over 50 years of age, one was obese, intubation was difficult and the procedure was performed in emergency conditions, the chest X-ray taken after intubation showed what looked like an overinflated cuff and the second one was a diabetic woman submitted to emergency stylet guided intubation.

Sudden subcutaneous emphysema at the cervical or thoracic level shortly after intubation is seen as a first sign in 64.8 to $80 \%$ of cases its amount depending on length and depth of the laceration [13]. Occasionally is accompanied by dyspnea thoracic pain and hemoptysis. Signs and symptoms may be delayed between 24 and 72 hours after the rupture and the only sign may be hemodynamic deterioration due to mediastinal shift facing which a high level of suspicion must be held and is mandatory to order immediately X-ray images in order to rule out a tracheal rupture. In ventilated patients is important not to confuse the hemodynamic compromise caused by positive airway pressure or PEEP with the one caused by mediastinal deviation secondary to pneumomediastinum or pneumothorax. Subcutaneous emphysema and arterial hypotension appeared very early in both cases presented, within minutes of connection to mechanical ventilation in the first and after two hours of ventilation in the second patient. As in $92 \%$ to $100 \%$ of cases, the chest X-ray picture was useful in showing extra pulmonary air in both patients, finding that was confirmed on CT scan of thorax. Chen JD et al. has demonstrated a sensibility of $85 \%$ for thoracic CT Scan in the diagnostic of tracheal rupture [14] and Faure A and collaborators give CT scan $100 \%$ of sensibility and $82 \%$ specificity with a positive and negative predictive values of $87 \%$ and $100 \%$ respectively when using multiplanar reconstruction of images [15]. Most common findings are: subcutaneous air in $76.6 \%$, pneumomediastinum in $66.6 \%$ of cases, pneumopericardium, pneumothorax, pneumoperitoneum [9] and lost of continuity of tracheal wall occasionally with cuff herniation through the laceration backward from the posterior wall of the trachea or the protrusion of the anterior wall of the esophagus into the tracheal lumen.

Definite diagnosis is made by tracheobronchoscopy which will enable to clarify location, length and depth of the rupture and therefore to plan the most appropriated treatment. Final prognosis of tracheal rupture depends both on the underlying disease and baseline state of the patient, seriousness of the injure and on the precocity of diagnosis. According to Miñambres et al., overall mortality of tracheal rupture reaches $22 \%$ being important in this regard the absence of subcutaneous emphysema that may lead to delayed diagnosis [16].

Our diagnostic approach was in line with that described in the reviewed literature. Immediate diagnosis and treatment was established in our first case with a suspicious X-ray, a diagnostic CT scan and confirmatory and therapeutic bronchoscopy and discreetly delayed at the second day of evolution in the second patient.

There are no guidelines for treatment of this condition; although most authors recommend surgical treatment there is no concensus on what approach is the most convenient one. The objectives of treatment must be to prevent progressive air leak into mediastinum or pleural space and avoid mediastinitis by restoring as soon as possible the normal tracheal anatomy. Early repair and broad antibiotic coverture within 24 hours appears to be the ideal scenario. In cases of upper third laceration the transcervical or tracheostomy suture approach is recommended [17] [18].

In medium or distal third lesions a right posterolateralthoracotomy using intercostal muscle flap to buttress the tracheal suture is the most performed technique. However, with surgical approach there is always the risk of wound infection, leaking of sutures, post operative tracheal stenosis and fistulas [19]. Alternatives to this surgery are the realization of a decompression tracheostomy in order to wait for the spontaneous healing of the defect, the use of fixed or removable stents and lately the intraluminal suture using an optical needle holder with 
telescope which avoids surgical access but needs high frequency jet ventilation, not available everywhere, to obtain good ventilation and less movement of the site of operation [19]-[22].

A more conservative method in small superficial lesions is to isolate such injury, through an endotracheal tube with the cuff distal to the lesion which needs a very close and permanent monitoring of cuff pressure so to avoid mucosal damage due to the presence of the tube itself [23]. However, the important point is which patients will benefit with an aggressive treatment and which will do with more conservative measures

In the series of Cardillo et al. on 2010 a classification of tracheal ruptures according to depth into three levels is described:

Level I-mucosal or submucosal tracheal involvement without mediastinal emphysema and without oesophageal injury

Level II-tracheal lesion up to the muscular wall with subcutaneous or mediastinal emphysema without oesophageal injury or mediastinitis.

Level IIIA-complete laceration of the tracheal wall with oesophageal or mediastinal soft-tissue hernia without oesophageal injury or mediastinitis.

Level IIIB - any laceration of the tracheal wall with oesophageal injury or mediastinitis.

According to the level of injury, he proposes a conservative or surgical approach. Level I and II should be treated non surgically; level IIIA could be treated conservatively if clinical conditions permit it so that is, if patient is not being ventilated, is not in respiratory distress or if is not hemodinamically unstable and level IIIB should always treated as soon as possible by surgery [9].

Both cases 1 and 2 correspond to Cardillo's Level III A. He proposes conservative treatment with local instillation of a fibrin glue (Tissucol) if the patient has an adequate respiratory status otherwise he proceeds directly to surgery [9]. Both of our patients were in overt respiratory distress but their general baseline condition anticipated a very torpid post operatory evolution if submitted to surgery therefore we preferred to perform local treatment with PRP instead of using a commercially available fibrin glue because being an autologous material it doesn't have neither bovine fibrin nor multiple donors fibrinogen obviating the risk of hypersensitivity reactions and the transmission of infectious diseases such as AIDS, hepatitis or other viral infections [24]-[26].

To our knowledge there are no communications on the use of PRP to repair tracheal ruptures in humans. We have found only two references of experimental work with PRP on airway lesions. Gomez-Caro et al. in an experimental pig model of tracheal resection and end to end anastomosis with local PRP application show that this substance accelerates the onset of healing by promoting an earlier release of platelet derived growth factors that stimulate transanastomotic angiogenesis thus reducing complications of surgery [27] and Spartalis et al. obtain accelerated granulation of the bronchial stump after pneumonectomy in pigs by locally applying a clot of PRP covering the bronchial suture line [28].

As we have previously shown, PRP is easily produced with minimal basic equipment and we can manage the speed of platelet activation to obtain immediate or delayed liberation of growth factors from platelets in situ. Platelets contained in the PRP fraction are activated by the addition of $\mathrm{CaCl} 10 \%$ which transforms the endogenous prothrombine into thrombine that in turn determines the transformation of fibrinogen to a fibrin net under which platelets rich in growth factors aggregate and become activated. Once activated, platelets start to degranulate liberating the growth factors contained particularly on Alfa granules. This process lasts about 3 minutes and can be accelerated by increasing temperature or by activating platelets in situ by using a double lumen catheter. Through one of the lumens passes PRP and through the other, the $\mathrm{CaCl}$ in order to produce activation of platelets right on the site to be treated [29]. The secretory proteins contained in the alfa granules help healing by attracting mesenquimal undifferentiated cells into the site of injury and at the mean time, triggering cell division. In this way, regeneration and noeformation of matrix is obtained by proliferation of fibroblasts and new capillary growth. The process continues by synthesizing additional growth factors locally up to 8 days after which platelets lose their vitality. Therefore the process is an auto limited one causing immediate onset of repairing inflammatory mechanisms but not persistent on time and thus, without the risk of promoting chronic granulation and endoluminal fibrosis with secondary distortion or stenosis.

In our experience in these two cases we observed an almost immediate effect as demonstrated by tracheobronchoscopic and CT early control with no complication thereafter as shown by long term endoscopic and imaging monitoring. Final result was the obtaining of prompt and complete recovery of tracheal anatomy without having to refer patients to surgery in order to submit them to high risk aggressive therapies with an uncertain 
outcome.

\section{Conclusions}

1) Diagnosis of post intubation tracheal rupture requires a high degree of suspicion and must be based on early images and endoscopic examination of the airway.

2) We can assert that PRP is not expensive and easy to obtain.

3) PRP was safely administered to our patients without adverse events.

4) It has a rapid onset of action being significantly effective.

5) Being a minimally invasive procedure, it can be applied to frail patients even in extensive lacerations avoiding exposition to more risky therapies.

\section{References}

[1] Whiteheart, S.W. (2011) Platelets Granules: Surprise Packages. Platelets and Thrombopoiesis. Blood, 118, $1190-1191$.

[2] Gunning, W. (2003) The Platelet Delta Granule and Its Role in Hemostasis. Microscopy and Microanalysis, 9, 13621363.

[3] Ciferri, S., et al. (1998) Platelets Release Lambda-Granules (Lysosimes) in Vivo in Humans upon Activation. Thrombosis Research, 91, 36.

[4] Lee, J.W., Kwon, O.H., Kim, T.K., Cho, Y.K., Choi, K.Y., Chung, H.Y., et al. (2013) Platelet Rich Plasma: Quantitative Assessment of Growth Factor Levels and Comparative Analysis of Activated an Inactivated Groups. Archives of Plastic Surgery, 40, 530-535. http://dx.doi.org/10.5999/aps.2013.40.5.530

[5] Chang, C.-Y., Cheng, S.-L. and Chang, S.-C. (2011) Conservative Treatment of Severe Tracheal Laceration after Endotracheal Intubation. Respiratory Care, 56, 861-862. http://dx.doi.org/10.4187/respcare.00891

[6] Chen, E.H., Logman, Z.M., Glass, P.S.A. and Bilfinger, T.V. (2001) A Case of Tracheal Injury after Emergency Endotracheal Intubation: A Review of the Literature and Causalities. Anesthesia \& Analgesia, 93, 1270-1271. http://dx.doi.org/10.1097/00000539-200111000-00047

[7] Ramos Izquierdo, R., Moya Amoròs, J., Morera Abad, R., Pujol Rovira, R., Perna, V. and Ferrer Recuero, G. (2006) Iatrogenic Tracheal Ruptura after Endotracheal Intubation. Cirugía Española, 80, 46-48. http://dx.doi.org/10.1016/S0009-739X(06)70916-2

[8] Massard, G., Rougè, C., Dabbagh, A., Kessler, R., Hentz, J.G., Roeslin, N., Wihlm, J.M. and Morand, G. (1996) Tracheobronchial Lacerations after Intubation and Tracheostomy. Annals of Thoracic Surgery, 61, 1483-1487. http://dx.doi.org/10.1016/0003-4975(96)00083-5

[9] Cardillo, G., Carbone, L., Carleo, F., Batzella, S., Jacono, R.D., Lucantoni, G. and Galluccio, G. (2010) Tracheal Lacerations after Endotracheal Intubation: A Proposed Morphological Classification to Guide Non-Surgical Treatment. European Journal of Cardio-Thoracic Surgery, 37, 581-587. http://dx.doi.org/10.1016/j.ejcts.2009.07.034

[10] Ovari, A., Justi, T., Dommerich, S., Hingst, V., Bôttcher, A., Schuldt, T., Guder, E., Mencke, T. and Pau, H.W. (2014) Conservative Management of Post Intubation Tracheal Tears-Report of Three Cases. Journal of Thoracic Disease, 6 , E85-E91.

[11] Dettmeyer, R.B., Schütz, H.F. and Verhoff, M.A. (2013) Forensic Medicine: Fundamentals and Perspectives. Berlin, Heidelberg.

[12] Tewfick, T.L. and Gest, T.R. (2013) Trachea Anatomy. Medscape.

[13] Hayi-Slayman, D., Page, M., Ben Cheikh, A., Christin, F., Ber, C.E. and Rimmelè, T. (2007) Tracheal Rupture after Orotracheal Intubation in Intensive Care. Annales Françaises d'Anesthésie et de Réanimation, 26, 600-603.

[14] Chen, J.D., Shanmuganathan, K., Mirvis, S.E., Killeen, K.L. and Dutton, R.P. (2001) Using CT to diagnose tracheal rupture. American Journal of Roentgenology, 176, 1273-1280. http://dx.doi.org/10.2214/ajr.176.5.1761273

[15] Faure, A., Floccard, B., Pilleul, F., Faure, F., Badinand, B., Mennesson, N., Ould, T., Guillaume, C., Levrat, A., Benatir, F. and Allaouchiche, B. (2007) Multiplanar Reconstruction: A New Method for the Diagnosis of Tracheobronchial Rupture? Intensive Care Medicine, 33, 2173-2178.

[16] Miñambres, E., Buron, J., Ballesteros, M.A., Llorca, J., Muñoz, P. and Gonzalez-Castro, A. (2009) Tracheal Rupture after Endotracheal Intubation: A Literature Systematic Review. European Journal of Cardio-Thoracic Surgery, 35, 1056-1062. http://dx.doi.org/10.1016/j.ejcts.2009.01.053

[17] Park, I.K., Lee, J.G., Lee, C.Y., Kim, D.J. and Chung, K.Y. (2007) Transcervical Intraluminal Repair of Posterior Membranous Tracheal Laceration through Semi-Lateral Transverse Tracheotomy. The Journal of Thoracic and Cardiovascular Surgery, 134, 1597-1598. http://dx.doi.org/10.1016/j.jtcvs.2007.09.001 
[18] Ambrogi, M.C., Mussi, A., Ribechini, A. and Angeletti, C.A. (2001) Posterior Wall Laceration of the Thoracic Trachea: The Transcervical-Transtracheal Approach. European Journal of Cardio-Thoracic Surgery, 19, 932-934. http://dx.doi.org/10.1016/S1010-7940(01)00678-9

[19] Lyons, J.D., Feliciano, D.V., Wyrzykowski, A.D. and Rozycki, G.S. (2013) Modern Management of Penetrating Tracheal Injuries. American Surgeon, 79, 188-193.

[20] Nazari, S., Buniva, P., Aluffi, A., Salvi, S. and Mourad, Z. (1999) Decompressing Tracheostomy for the Treatment of Post Intubation Tracheal Rupture. The Annals of Thoracic Surgery, 68, 1122-1125.

[21] Creagh-Brown, B., Sheth, A., Crerar-Gilbert, A. and Madden, B.P. (2008) A Novel Approach to the Management of Acute Tracheal Tear. The Journal of Laryngology Otology, 122, 1392-1393.

[22] Welter, S., Krbek, T., Halder, R. and Stamatis, G. (2011) A New Technique for Complete Intraluminal Repair of Iatrogenic Posterior Tracheal Lacerations. Interactive Cardiovascular and Thoracic Surgery, 12, 6-9. http://dx.doi.org/10.1510/icvts.2010.248641

[23] Steindor, M., Schuster, A., Hoehn, T., Mayatepek, E., Santos, M., Angenendt, S., Klee, D. and Schramm, D. (2014) Conservative Treatment of Tracheal Injuries. Journal of Pediatric Surgery Case Reports, 2, 294-296.

[24] Wilson, S.M., Pell, P. and Donegan, E.A. (1991) HIV-1 Transmission Following the Use of Cryoprecipitate Fibrinogen as Gel/Adhesive. Transfusion, 31, 51S.

[25] Hino, M., Ishiko, O., Hinda, K.I., Yamane, T., Ohta, K., Takubo, T. and Tatsumi, N. (2000) Transmission of Symptomatic Parvovirus B19 Infection by a Fibrin Sealant Used during Surgery. British Journal of Haematology, 108, 195195. http://dx.doi.org/10.1046/j.1365-2141.2000.01818.x

[26] Milde, L.M. (1989) An Anaphylactic Reaction to Fibrin Glue. Anesthesia \& Analgesia, 69, 684-686. http://dx.doi.org/10.1213/00000539-198911000-00026

[27] Gomez-Caro, A., Ausin, P. and Boada, M. (2012) Platelet Rich Plasma Improves the Healing Process after Airway Anastomosis. Interactive Cardiovascular and Thoracic Surgery, 13, 552-556. http://dx.doi.org/10.1510/icvts.2011.273995

[28] Spartalis, E., Tomos, P., Konofaos, P., Karagkiouzis, G., Levidou, G., Kavantzas, N., Pantopoulou, A., Michail, O., Perrea, D. and Kouraklis, G. (2013) The Effect of Autologous Platelet-Rich Plasma on Bronchial Stump Tissue Granulation after Pneumonectomy: Experimental Study. International Scholarly Research Notices Surgery, 2013, Article ID: 864350 .

[29] Rioseco, P., Cespedes, V., Muñoz, S., Tapia, S. and Vasquez, D. (2014) Utilidad del plasma rico en plaquetas en neumología. Revista chilena de enfermedades respiratorias, 30, 156-165. http://dx.doi.org/10.4067/S0717-73482014000300005 